\title{
SOMATOSTATIN REGULATES DOPAMINE RELEASE IN RAT STRIATAL SLICES AND CAT CAUDATE NUCLEI ${ }^{1}$
}

\author{
MARIE-FRANCOISE CHESSELET ${ }^{2}$ AND TERRY D. REISINE ${ }^{3}$ \\ Groupe NB, Instilut National de la Santé et de la Recherche Médicale, U 114, College de France, 11 place Marcelin \\ Berthelot, Paris 75231, France
}

Received April 28, 1982; Revised July 29, 1982; Accepted August 3, 1982

\begin{abstract}
The effects of somatostatin on the release of tritiated dopamine (DA) formed continuously from tritiated tyrosine were studied in vitro in superfused striatal slices and in vivo in both caudate nuclei and both substantiae nigrae of halothane-anesthetized cats using a push-pull cannula technique. Somatostatin $\left(3 \times 10^{-10}\right.$ to $\left.3 \times 10^{-7} \mathrm{M}\right)$ increased the spontaneous tritiated dopamine release from rat striatal slices. This effect was dose dependent and was completely prevented by tetrodotoxin ( 5 $\left.\times 10^{-7} \mathrm{M}\right)$. When applied for $30 \mathrm{~min}$ in one cat caudate nucleus, somatostatin $\left(10^{-7} \mathrm{M}\right)$ immediately increased the local release of tritiated DA, while a gradual inhibition of the tritiated amine's efflux was observed in the contralateral caudate nucleus. No changes in tritiated dopamine were seen in either substantia nigra during or after the peptide's application in the caudate nucleus. These results suggest that somatostatin in the striatum may play a role in the local and the distal control of dopamine release from the terminals of dopaminergic nigrostriatal neurons.
\end{abstract}

Somatostatin, originally described as a hypothalamic neurohormone (see Reichlin, 1980) has been thought in the past few years to function as a neurotransmitter in the central nervous system. In fact, the uneven distribution of this peptide in the brain (Kobayashi et al., 1977), its presence in nerve terminals (Epelbaum et al., 1977), and its electrophysiological effects (see Reichlin, 1980) suggest that it may have a role in neurotransmission or neuromodulation. Furthermore, somatostatin can be released from brain slices through a calcium-dependent mechanism (Lee and Iversen, 1981) and may act on specific receptors (Reubi et al., 1981; Srikant and Patel, 1981) which have been characterized in binding studies using radioactive analogues of the peptide. Such specific binding sites (Reubi et al., 1981; Srikant and Patel, 1981) as well as somatostatin-like immunoreactive neurons (Graybiel et al., 1981) have been described in the stria-

\footnotetext{
${ }^{1}$ We thank Dr. Solange Lavielle for the generous gift of somatostatin. Dr. Jacques Glowinski and Andre Cheramy for helpful discussion, and M. Desban for assistance. This work was supported by Grant ATP 58.78.90 from Institut National de la Santé et de la Recherche Médicale, DRET Grant 78.004, and Rhone Poulenc S.A. T. D. R. is a National Institute of Neurological and Communicative Disorders and Stroke Fellow (1F32NSQ6467.01).

${ }^{2}$ To whom correspondence should be addressed at Department of Psychology and Brain Sciences, Massachusetts Institute of Technology, Cambridge, MA 02139.

${ }^{3}$ Present address: Laboratory for Clinical Science, National Institutes of Health-National Institute of Mental Health, Building 10, Room 2D45, Bethesda, MD 20205.
}

tum. However, the function of somatostatin in this structure is totally unknown.

Numerous striatal neurotransmitters have been shown to modulate the release of dopamine (DA) from dopaminergic nigrostriatal neurons, a major afferent input to the striatum (see Giorguieff-Chesselet et al., 1980). When injected intracerebroventricularly, somatostatin induced an increase in DA synthesis and turnover in several brain areas including the striatum (Garcia-Sevilla et al., 1978). Therefore, one possibility may be that somatostatin plays a role in the local regulation of striatal dopaminergic transmission. This hypothesis was investigated in the present study by measuring the effect of somatostatin on the release of tritiated dopamine $\left(\left[{ }^{3} \mathrm{H}\right] \mathrm{DA}\right)$ newly synthesized from $\left[{ }^{3} \mathrm{H}\right]$ tyrosine. Experiments were carried out both in vitro in rat striatal slices and in vivo in the two caudate nuclei $(\mathrm{CN})$ and substantiae nigrae of halothaneanesthetized cats, using a push-pull cannula technique. It will be shown that somatostatin applied in low concentration in the striatum not only locally increased $\left[{ }^{3} \mathrm{H}\right] \mathrm{DA}$ release but also affected striatal efferents which modulate the activity of the contralateral nigrostriatal dopaminergic pathway.

\section{Materials and Methods \\ In vitro experiments}

Striatal slices $(0.3 \mathrm{~mm}$ thickness) of male SpragueDawley rats (200 to $500 \mathrm{gm}$ ) were prepared and superfused as described previously (Giorguieff et al., 1977). 
Briefly, slices from one striatum (50 $\mathrm{mg}$ of tissue) were put in microsuperfusion chambers $(200 \mu \mathrm{l})$, maintained at $37^{\circ} \mathrm{C}$, and superfused at a rate of $2 \mathrm{ml} / \mathrm{hr}$ with an artificial oxygenated cerebrospinal fluid containing 50 $\mu \mathrm{Ci} / \mathrm{ml}$ of $\mathrm{L}-\left[3,5-{ }^{3} \mathrm{H}\right]$ tyrosine $(50 \mathrm{Ci} / \mathrm{mmol})$. The $\left[{ }^{3} \mathrm{H}\right] \mathrm{ty}-$ rosine was purified, prior to the experiment, by high pressure liquid chromatography (Cheramy et al., 1981). Superfusates were collected every $2.5 \mathrm{~min}$ on a protective solution $\left(40 \mu \mathrm{l}\right.$ of thioglycolic acid, $\left.10^{-3} \mathrm{M}\right)$ on ice and stored at $-20^{\circ} \mathrm{C}$, after addition of $2 \mathrm{ml}$ of absolute ethanol, for no longer than $72 \mathrm{hr}$ before the biochemical analysis.

\section{In vivo experiments}

Cats of both sexes ( 2 to $3 \mathrm{~kg}$ ) were anesthetized with halothane $(3 \%)$, artificially ventilated through tracheotomy, monitored, and held stereotaxically as described previously (Cheramy et al., 1981). One push-pull cannula was introduced in each $\mathrm{CN}$ and each substantia nigra according to the following coordinates: $\mathrm{CN}, A=16, L=$ 4.5, $H=5$; substantia nigra, $A=4, L=3, H=-5$. Each push-pull cannula was supplied continuously $(300 \mu \mathrm{l} / 10$ min) with an artificial cerebrospinal fluid containing 50 $\mu \mathrm{Ci} / \mathrm{ml}$ of $\left[{ }^{3} \mathrm{H}\right]$ tyrosine prepared as described above. Superfusates were collected in successive 10-min fractions in tubes containing an ice-cold stabilizing thioglycolic acid solution $\left(10^{-2} \mathrm{M}\right.$ final concentration). Ethanol (1 ml) was added immediately to the collected fractions and samples were stored at $-20^{\circ} \mathrm{C}$ until biochemical analysis was performed.

\section{Histological controls}

At the end of each experiment, the cat was perfused through the carotid artery with $10 \%$ formalin in isotonic saline under deep halothane anesthesia. Serial frontal sections of the brain were stained with cresyl violet and were submitted to histological control to determine the sites of superfusion.

\section{Biochemical analysis}

For both the in vitro and in vivo release studies, $\left[{ }^{3} \mathrm{H}\right]$ DA was separated from L- $\left[3,5-{ }^{3} \mathrm{H}\right]$ tyrosine, ${ }^{3} \mathrm{H}$-metabolites, and ${ }^{3} \mathrm{H}$-radiolysis compounds as described previously (Cheramy et al., 1981). Briefly, samples were passed through an Amberlite and an alumina column, and $\left[{ }^{3} \mathrm{H}\right]$ DA present in the eluates was estimated by liquid scintillation spectrometry. Data were corrected for recovery (75\%). The mean level of $\left[{ }^{3} \mathrm{H}\right] \mathrm{DA}$ recovered in each fraction was 10 to 20 times the blank value which was identical to the counter background.

\section{Data presentation and analysis}

1. In vitro studies. In these experiments, drugs were added for either 7.5 or $17.5 \mathrm{~min}$ in the superfusion medium, 25 min after the beginning of the superfusion. Previously, we have shown (Giorguieff et al., 1977) that the spontaneous efflux of newly synthesized $\left[{ }^{3} \mathrm{H}\right] \mathrm{DA}$ in continuously superfused striatal slices is calcium dependent, a characteristic of the physiological release of the transmitter. In control slices (no drugs added), it should be noted that the spontaneous release of $\left[{ }^{3} \mathrm{H}\right] \mathrm{DA}$ after an initial 15-min labeling period slowly increased as a function of time. In each experiment, $\left[{ }^{3} \mathrm{H}\right] \mathrm{DA}$ in each successive fraction was expressed as a percentage of an average spontaneous release calculated from the three fractions collected before the treatment. The changes in percentage of $\left[{ }^{3} \mathrm{H}\right] \mathrm{DA}$ release during the drug treatments then were compared to $\left[{ }^{3} \mathrm{H}\right] \mathrm{DA}$ release occurring in controls.

In the experiments with tetrodotoxin, the neurotoxin was added to the superfusion medium at the beginning of each trial. This treatment has been shown previously to reduce the spontaneous release of $\left[{ }^{3} \mathrm{H}\right] \mathrm{DA}$ (Giorguieff et al., 1977). The application of somatostatin then was carried out in a similar fashion as described for the other experiments, and changes in $\left[{ }^{3} \mathrm{H}\right] \mathrm{DA}$ release were compared to values obtained in slices superfused in the presence of tetrodotoxin alone.

2. In vivo studies. In each animal and for each cannula, $\left[{ }^{3} \mathrm{H}\right] \mathrm{DA}$ in each successive fraction was expressed as a percentage of an average spontaneous release calculated from the five fractions collected before the application of somatostatin. The results obtained in treated animals are compared to control (untreated) animals.

In all cases, statistics were determined using the twotailed Student's $t$ test with values of $p<0.05$ considered significant.

\section{Substances used}

Somatostatin was synthesized and generously donated by Dr. Solange Lavielle, Paris, France. Tetrodotoxin crystalline was purchased from Sankyo Co., Ltd., Tokyo, Japan. L- $\left[3,5-{ }^{3} \mathrm{H}\right]$ tyrosine was purchased from New England Nuclear, Boston, MA, or Commissariat à L'Energie Atomique, Gif s/Yvette, France.

\section{Results}

Effect of somatostatin on the spontaneous release of $\left[{ }^{3} \mathrm{H}\right]$ dopamine in vitro. In an initial study, a different concentration of somatostatin was added for $7.5 \mathrm{~min}$ to the superfusion medium of eight groups of striatal slices in the same experiment. Somatostatin in a concentration range from $3 \times 10^{-10}$ to $3 \times 10^{-7} \mathrm{M}$ increased $\left[{ }^{3} \mathrm{H}\right] \mathrm{DA}$ release above control values in a dose-dependent manner. This is shown in Figure 1, which represents the mean value of $\left[{ }^{3} \mathrm{H}\right] \mathrm{DA}$ released during three fractions of somatostatin's superfusion, expressed as a percentage of the mean value of $\left[{ }^{3} \mathrm{H}\right] \mathrm{DA}$ release measured in the three fractions preceding the peptide's application. These effective concentrations of somatostatin correspond to the affinity of specific brain binding sites for this peptide (Reubi et al., 1981; Srikant and Patel, 1981).

Further characterization of this effect was carried out by applying somatostatin, $10^{-9}$ or $10^{-7} \mathrm{M}$, for $15 \mathrm{~min}$ to rat striatal slices. The mean values of the results obtained in four or five experiments are reported in Figure 2. At both concentrations, somatostatin significantly increased the $\left[{ }^{3} \mathrm{H}\right] \mathrm{DA}$ release, this effect was slightly less pronounced with the lower concentration and, in both cases, lasted during the entire peptide's application.

Blockade of the somatostatin-enhanced $\left[{ }^{3} \mathrm{H}\right]$ dopamine release in rat striatal slices in the presence of tetrodotoxin. Tetrodotoxin $\left(5 \times 10^{-7} \mathrm{M}\right)$ was added to the superfusion medium throughout the entire experiment. This induces a decrease of approximately $50 \%$ of the $\left[{ }^{3} \mathrm{H}\right]$ 


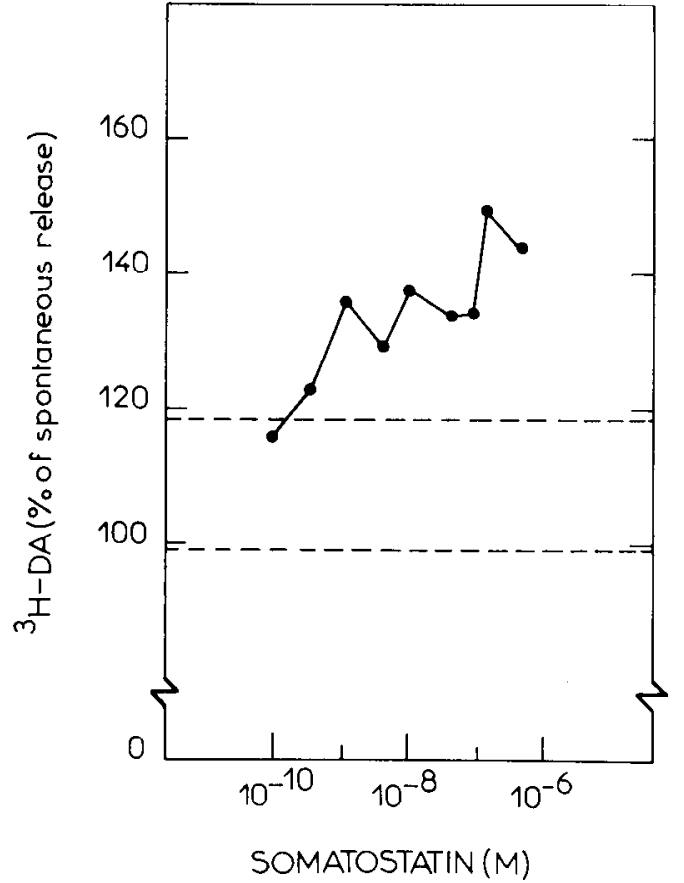

Figure 1. Effect of different concentrations of somatostatin on $\left[{ }^{3} \mathrm{H}\right]$ dopamine release in rat striatal slices. Rat striatal slices were superfused continuously with an artificial cerebrospinal fluid containing $\mathrm{L}-\left[3,5-{ }^{3} \mathrm{H}\right]$ tyrosine $(50 \mathrm{Ci} / \mathrm{mmol}, 50 \mu \mathrm{Ci} / \mathrm{ml})$. The $\left[{ }^{3} \mathrm{H}\right] \mathrm{DA}$ released was estimated in serial 2.5 -min superfusate fractions as described under "Materials and Methods." In one experiment, a different concentration of somatostatin was added into the superfusion medium of each group of slices for $7.5 \mathrm{~min}, 25 \mathrm{~min}$ after the onset of the superfusion. In each case, the mean value of $\left[{ }^{3} \mathrm{H}\right] \mathrm{DA}$ release during the peptide's application (three values) was expressed as a percentage of the spontaneous release observed during three fractions of superfusion before the application in the same group of slices. The hatched bar represents the mean \pm SEM range of $\left[{ }^{3} \mathrm{H}\right] \mathrm{DA}$ release in five control, untreated slices during the same period of time.
DA efflux, the reduction being unrelated to an inhibition of $\left[{ }^{3} \mathrm{H}\right]$ tyrosine uptake in striatal slices (Giorguieff et al., 1977). Under these conditions, somatostatin $\left(10^{-7} \mathrm{M}\right)$ did not induce any significant changes in $\left[{ }^{3} \mathrm{H}\right] \mathrm{DA}$ release when compared to slices continuously superfused with a medium containing the toxin $\left(5 \times 10^{-7} \mathrm{M}\right)$ alone (Fig. 2).

In vivo effect of somatostatin on $\left[{ }^{3} \mathrm{H}\right]$ dopamine release in both caudate nuclei and substantiae nigrae in the cat. The spontaneous release of newly synthesized $\left[{ }^{3} \mathrm{H}\right] \mathrm{DA}$ was measured in both $\mathrm{CN}$ and both substantiae nigrae of halothane-anesthetized cats, by means of pushpull cannulae. Somatostatin $\left(10^{-7} \mathrm{M}\right)$ added for $30 \mathrm{~min}$ to the superfusion medium of one $\mathrm{CN}$ induced an immediate, marked $(250 \%)$ but short lasting (10 $\mathrm{min})$ local increase of $\left[{ }^{3} \mathrm{H}\right] \mathrm{DA}$ release. By contrast, in the contralateral $\mathrm{CN}$, a progressive decrease of the ${ }^{3} \mathrm{H}$-amine outflow appeared during and after somatostatin's application. No significant changes in $\left[{ }^{3} \mathrm{H}\right] \mathrm{DA}$ release were observed in the two substantiae nigrae (Fig. 3 ).

\section{Discussion}

The present results reveal that somatostatin increases DA release when locally applied to rat striatal slices or in the cat $\mathrm{CN}$. The dose-dependent increase in $\left[{ }^{3} \mathrm{H}\right] \mathrm{DA}$ spontaneous release, induced in vitro by concentrations of somatostatin as low as $3 \times 10^{-10} \mathrm{M}$, suggests that this neuropeptide, which normally is present in the striatum (Kobayashi et al., 1977; Graybiel et al., 1981), may contribute to a local regulation of the striatal dopaminergic transmission. However, due to the lack of specific blocker for somatostatin's receptors, it is presently impossible to further confirm the role of endogenous somatostatin in this regulatory process. Several other putative neurotransmitters or agonists of transmitter receptors have already been shown to affect newly synthetized $\left[{ }^{3} \mathrm{H}\right] \mathrm{DA}$ release in the striatum (see Giorguieff-Chesselet et al., 1980; Lubetzki et al., 1982; Reisine et al., 1982). The

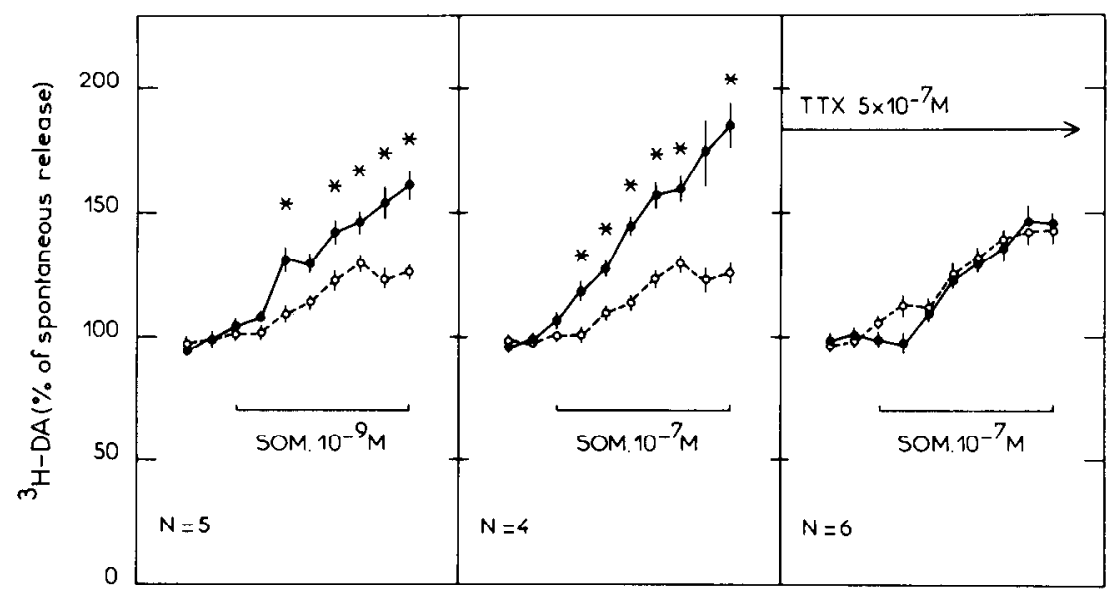

Figure 2. Effect of somatostatin in the absence and in the presence of tetrodotoxin on [ $\left.{ }^{3} \mathrm{H}\right]$ dopamine release in rat striatal slices. Experiments were performed essentially as described in Figure 1, except that somatostatin (SOM) was applied for 17.5 min, 25 min after the onset of the superfusion. The left and middle panels represent the mean \pm SEM of results obtained in $N$ number of experiments (- -$)$ and compared to the corresponding untreated $(N=6)$ control values $(-\bigcirc-), *, p<0.05$. The right panel represents the results of experiments in which tetrodotoxin $\left(5 \times 10^{-7} \mathrm{M}\right)$ was added to control $(-O-; N=5)$ as well as to somatostatin-treated $\left(10^{-7} \mathrm{M}\right)\left(-\frac{-}{2}=6\right)$ slices at the beginning of the superfusion with [ $\left.{ }^{3} \mathrm{H}\right]$ tyrosine. 


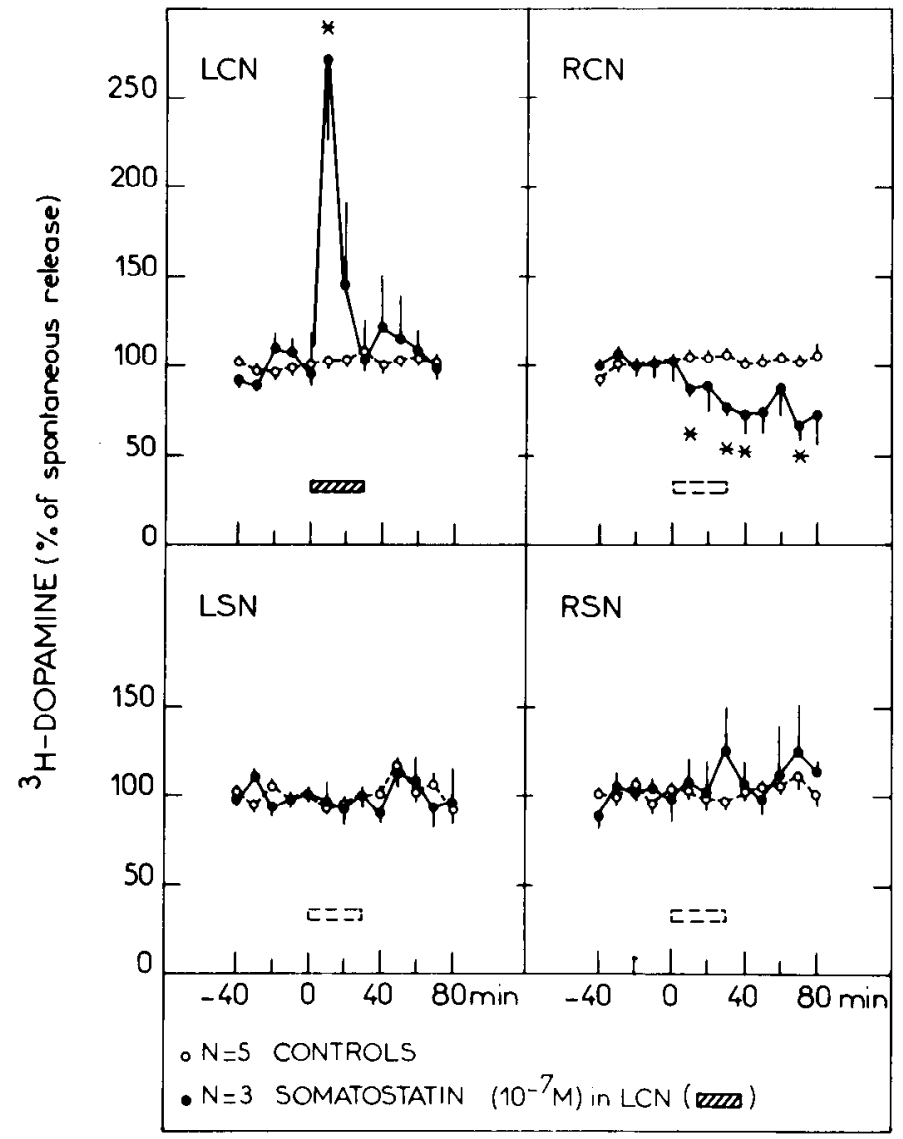

Figure 3. Effect of somatostatin on the in vitro release of $\left[{ }^{3} \mathrm{H}\right] \mathrm{DA}$ from the two substantiae nigrae and the two caudate nuclei in the cat. Four push-pull cannulae were implanted simultaneously in the left $(L C N)$ and the right $(R C N)$ caudate nuclei and the left $(L S N)$ and the right $(R S N)$ substantiae nigrae in halothane-anesthetized cats. The artificial cerebrospinal fluid delivered to the four push-pull cannulae contained $\mathbf{L}$ $\left[3,5-{ }^{3} \mathrm{H}\right]$ tyrosine $\left(50 \mathrm{Ci} / \mathrm{mm} u \mathrm{l}, 50 \mu \mathrm{Ci} / \mathrm{ml}, 1.8 \mathrm{ml} / \mathrm{hr}\right.$ ), and $\left[{ }^{3} \mathrm{H}\right]$ DA was estimated in 10 -min successive superfusate fractions. Somatostatin $\left(10^{-7} \mathrm{M}\right.$ ) was added for $30 \mathrm{~min}$ (hatched bar) into the superfusing medium of the left caudate nucleus. The open, dashed rectangles represent the time during which somatostatin was applied in the LCN. Data are the mean \pm SEM of results obtained with three treated animals (-O). $*, p<0.05$ when compared with corresponding control values (-O-).

actions of these compounds are blocked by specific receptor antagonists and can also be differentiated by their varying sensitivity to tetrodotoxin. In fact, whereas the effects of acetylcholine, glutamic acid (see GiorguieffChesselet et al., 1980), D-Ala 2 -Met-enkephalinamide (Lubetzki et al., 1982), and $\beta$-adrenergic agonists (Reisine et al., 1982) persist in the presence of tetrodoloxin, the enhancement of $\left[{ }^{3} \mathrm{H}\right] \mathrm{DA}$ release induced by GABA (see Giorguieff-Chesselet et al., 1980) or by somatostatin was suppressed by this neurotoxin. The similarity between GABA's and somatostatin's effects is of potential importance since it has been shown in immunohistochemical studies of the nucleus reticularis thalami (Oertel et al., 1981) that some brain neurons may contain both GABA and somatostatin. Because tetrodotoxin prevents action potentials, its blockade of somatostatin-induced $\left[{ }^{3} \mathrm{H}\right] \mathrm{DA}$ release suggests that the peptide, instead of acting directly on dopaminergic nerve terminals, activates interneurons modulating dopaminergic transmission. However, a direct action of somatostatin on dopaminergic nerve terminals cannot be totally excluded since tetrodotoxin may have impaired the peptide's effect by inducing a change in the membrane potential of dopaminergic nerve terminals (see Giorguieff-Chesselet et al., 1980).

Application of somatostatin to the cat $\mathrm{CN}$ in vivo induced an increase in local $\left[{ }^{3} \mathrm{H}\right] \mathrm{DA}$ release which was more pronounced than its in vitro effect. This could be due either to a species difference in somatostatin's receptor sensitivity or to a dependence of somatostatin's action on the activity of nigrostriatal dopaminergic neurons. Interestingly, by contrast to other agents which also increase the ${ }^{3} \mathrm{H}$-amine's release in the cat $\mathrm{CN}$ (see Giorguieff-Chesselet et al., 1980; Chesselet et al., 1981; Reisine et al., 1982), somatostatin did not induce a second stimulation of $\left[{ }^{3} \mathrm{H}\right] \mathrm{DA}$ outflow when removed from the superfusion medium. This clearly shows that the peptide interacts with dopaminergic neurons through mechanisms different from those of other striatal transmitters. Somatostatin's unique action is further supported by the effect induced in the contralateral CN. In fact, when similar experiments were performed with other transmitters or transmitter agonists (Chesselet et al., 1982; Reisine et al., 1982) which also locally increased $\left[{ }^{3} \mathrm{H}\right] \mathrm{DA}$ efflux, no effect was observed in the contralateral structures examined. This suggests that changes in DA release in one $\mathrm{CN}$ are not the primary cause for alterations in the amine outflow in the contralateral $\mathrm{CN}$. On the other hand, this contralateral effect cannot be due to the peptide's diffusion from the striatum since the volume of tissue superfused in our experimental conditions does not exceed about $4 \mathrm{~mm}^{3}$ around the tip of the cannula (Chesselet et al., 1982). Therefore, the decrease of $\left[{ }^{3} \mathrm{H}\right] \mathrm{DA}$ release in the contralateral $\mathrm{CN}$ is most probably related to an action of somatostatin on other striatal neurons or afferences in addition to the dopaminergic nerve endings.

This result brings new insights into the regulation of dopaminergic systems. The existence of a reciprocal relationship between the two nigrostriatal dopaminergic pathways has been demonstrated over the past few years (see Glowinski et al., 1980). Changes in the activity of the contralateral dopaminergic neurons can be initiated by pharmacological manipulations in the substantia nigra and, in this case, the information's transfer seems to occur through the massa intermedia of the thalamus (Cheramy et al., 1981). The in vivo action of somatostatin reported in the present study shows that striatal efferents directly or indirectly affected by this peptide may also play a role in the regulation of contralateral striatal dopaminergic transmission. Whatever the anatomical support for somatostatin's distal effect on $\left[{ }^{3} \mathrm{H}\right] \mathrm{DA}$ release might be, these data suggest that the neuropeptide could intervene in the physiological regulation of extrapyramidal systems which are known to play a role in sensorymotor integration (see Glowinski et al., 1980). Furthermore, they extend previous findings showing that soma- 
tostatin, which is known to inhibit the release of several hypophysial and digestive hormones (see Reichlin, 1980), is able to increase the efflux of various brain transmitters. In fact, somatostatin has been shown to enhance the release of previously taken up $\left[{ }^{3} \mathrm{H}\right]$ noradrenaline in cortical slices (Tsujimoto and Tanaka 1981) and $\left[{ }^{3} \mathrm{H}\right]$ serotonin from the cortex, hippocampus, and hypothalamus in vitro (Tanaka and Tsujimoto, 1981). Whereas the concentrations used in these previous studies were much higher than those needed to increase $\left[{ }^{3} \mathrm{H}\right] \mathrm{DA}$ release in the striatum, these data taken together suggest that a presynaptic facilitation of catecholamine release may be a general action of somatostatin in different brain areas.

\section{References}

Cheramy, A., V. Leviel, F. Daudet, B. Guibert, M. F. Chesselet, and J. Glowinski (1981) Involvement of the thalamus in the reciprocal regulation of the two nigro-striatal dopaminergic pathways. Neuroscience 6: 2657-2668.

Chesselet, M. F., A. Cheramy, T. D. Reisine, and J. Glowinski (1981) Morphine and $\delta$-opiate agonists locally stimulate in vivo dopamine release in cat caudate nucleus. Nature 291: $320-322$.

Chesselet, M. F., A. Cheramy, T. D. Reisine, C. Lubetzki, M. Desban, and J. Glowinski (1982) Local and distal effects induced by unilateral striatal applications of opiates in the absence or in the presence of naloxone on the release of dopamine in both caudate nuclei and substantiae nigrae of the cat. Brain Res., in press.

Epelbaum J., P. Brazeau, D. Tsang, J. Brower, and J. B. Martin (1977) Subcellular distribution of radio-immunoassayable somatostatin in rat brain. Brain Res. 126: 309-323.

Garcia-Sevilla, J. A., T. Magnusson, and A. Carlsson (1978) Effect of intra-cerebroventricularly administered Somatostatin on brain monoamines turnover. Brain Res. 155: 159-164.

Giorguieff, M. F., M. L. LeFloc'h, J. Glowinski, and M. J. Besson (1977) Involvement of cholinergic presynaptic receptors of nicotinic and muscarinic types in the control of the spontaneous release of DA from striatal dopaminergic terminals in the rat. J. Pharmacol. Exp. Ther. 200: 535-544.

Giorguieff-Chesselet, M. F., A. Cheramy, and J. Glowinski (1980) In vivo and in vitro studies on the presynaptic control of dopamine release from nerve terminals of the nigro-striatal dopaminergic neurons. In Neurotransmitters and Their Receptors, U. Z. Littauer, Y. Dudai, I. Silman, V. I. Teichberg, and Z. Vogel, eds., pp. 33-47, John Wiley and Sons, Inc., New York.

Glowinski, J., M. F. Giorguieff, and A. Cheramy (1980) Regulatory processes involved in the control of the activity of the nigro-striatal dopaminergic neurons. In The Reticular Formation Revisited: Specifying Function of a Nonspecific Sys-

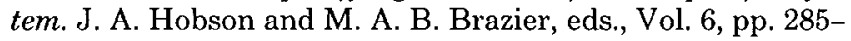
301, Raven Press, New York.

Graybiel, A. M., C. W. Ragsdale, E. S. Yoneoka, and R. P. Elde (1981) An immunohistochemical study of enkephalins and other neuropeptides in the striatum of the cat with evidence that the opiate peptides are arranged to form mosaic patterns in register with the striosomal compartments visible by acetylcholinesterase staining. Neuroscience 6: 377-397.

Kobayashi, R. M., M. Brown, and W. Vale (1977) Regional distribution of neurotensin and somatostatin in rat brain. Brain Res., 126: 584-588.

Lee, C. M., and L. L. Iversen (1981) Release of somatostatin from extra-hypothalamic rat brain slices: Inhibition by dopamine and morphine. Brain Res. 219: 355-361.

Lubetzki, C., M. F. Chesselet, and J. Glowinski (1982) Modulation of dopamine release in rat striatal slices by delta opiate agonists. J. Pharmacol. Exp. Ther. 222: 435-440.

Oertel, W., A. M. Graybiel, E. Mugnaini, R. Elde, D. Schmeckel, and I. Kopin (1981) Coexistence of glutamate decarboxylase immunoreactivity and somatostatin-like immuno-reactivity in neurones of nucleus reticularis thalami of the cat. Soc. Neurosci. Abstr. 7: 3.

Reichlin, S. (1980) Peptides in neuroendocrine regulation. In Peptides Integrators of Cell and Tissue Function, F. E. Bloom ed., pp. 235-250, Raven Press, New York.

Reisine, T. D., M. F. Chesselet, C. Lubetzki, A. Cheramy, and J. Glowinski (1982) A role for striatal beta-adrenergic receptors in the regulation of dopamine release. Brain Res. 241: $123-130$.

Reubi J. C., M. H. Perrin, J. E. Rivier, and W. Vale (1981) High affinity binding sites for a somatostatin-28 analog in rat brain. Life Sci. 28: 2191-2198.

Srikant, C. B., and Y. C. Patel (1981) Somatostatin receptors: Identification and characterisation in rat brain membranes. Proc. Natl. Acad. Sci. U. S. A. 78: 3930-3934.

Tanaka, S., and A. Tsujimoto (1981) Somatostatin facilitates the serotonin release from rat cerebral cortex, hippocampus and hypothalamus slices. Brain Res. 208: 219-222.

Tsujimoto, A., and S. Tanaka (1981) Stimulatory effect of somatostatin on norepinephrine release from rat brain cortex slices. Life Sci. 28: 903-910. 